\title{
Selective Antitumoral Effect of Sorafenib Loaded PLGA Nanoparticles Conjugated with Cetuximab on Undifferentiated/Anaplastic Thyroid Carcinoma Cells
}

Mato $\mathrm{E}^{2,3 \#}$, Puras $\mathrm{G}^{1,2 \#}$, Bell $\mathrm{O}^{2,3}$, Agirre $\mathbf{M}^{1,2}$, Hernández $\mathrm{RM}^{1,2}$, Igartua $\mathbf{M}^{1,2}$, Moreno $\mathbf{R}^{1}$, Gonzalez $\mathrm{G}^{2,3}$, de Leiva $\mathrm{A}^{2,3 *}$ and Pedraz $\mathrm{JL}^{1,2 *}$

${ }^{1}$ NanoBioCel Group, University of Basque Country, Vitoria, Spain

${ }^{2}$ Networking Research Centre of Bioengineering, Biomaterials and Nanomedicine (CIBER-BBN), Spain

${ }^{3}$ EDUAB-HSP Neoplasia Thyroid Study Group, IIB, Autonomous University, Barcelona, Spain

\#these authors contributed equally to this work

\begin{abstract}
Drug targeting represents a challenging approach with promising potential to circumvent some problems associated with many toxic effects of antineoplastics drugs. The objective of the present study was to develop PLGA nanoparticles surface modified with cetuximab to deliver in a targeted fashion sorafenib into undifferentiated/anaplastic thyroid carcinoma cell line as an efficient in vitro model.

Sorafenib loaded nanoparticles were obtained by the single emulsion evaporation method and characterized in terms of size $(252 \mathrm{~nm})$, charge $(-14.6 \mathrm{mV})$, morphology (spherical), drug entrapment efficiency $(58 \%)$ and in vitro drug release. Resulted nanoparticles were surface conjugated with monoclonal antibody cetuximab by EDC/Sulfo-NHS cross linking chemistry, without affecting significantly to their physicochemical properties. $51 \%$ of the cetuximab was incorporated into the surface of PLGA nanoparticles. Cellular uptake studies were performed with fluorescent (6-coumarin) PLGA nanoparticles and cetuximab conjugated fluorescent PLGA nanoparticles in both thyroid anaplastic (CAL-62) and normal thyroid cells (Nthy-ori 3-1). Confocal microscopy assays revealed that the capture of immunonanoparticles over the time showed a different pattern depending on the cell and the nanoparticles studies. In vitro antiproliferation assay based on MTT showed that sorafenib incorporated nanoparticles had a more cytotoxic effect on normal thyroid Nthy-ori 3-1 cells than on anaplastic thyroid CAL-62 cells. However, cetuximab conjugated nanoparticles reverted the cytotoxicity profile, showing a lower cytotoxic effect on normal thyroid Nthy-ori 3-1 cells when compared with anaplastic thyroid CAL-62 cells. These data suggest that sorafenib-PLGA nanoparticles surface modified with cetuximab represent a new and promising targeting approach for the treatment of epithelial thyroid cancer.
\end{abstract}

Keywords: Sorafenib; Cetuximab; Drug delivery; PLGA nanoparticles; Thyroid carcinoma

\section{Introduction}

Although the epithelial thyroid cancer has a good prognosis, $2 \%$ to $5 \%$ of these tumours may lose their differentiated characteristics with fatal consequences [1]. They lose the ability to capture radioactive iodine (RAI), becoming radioactive iodine-refractory tumours, which increases the probability to induce regional and distant metastasis, being in many cases not possible to undergo surgical resection. Currently, for these subtypes of differentiated thyroid cancers (DTC) refractory to RAI with an aggressive behaviour, there are no efficacious systemic therapies, although several small-molecule tyrosine kinase inhibitors (TKIs) directed towards gene mutations (RET and BRAF) have been tested in preclinical and also in clinical trial studies. One of these molecules is sorafenib, which is actually recommended as a treatment option for primary kidney cancer (advanced renal cell carcinoma) and for advanced primary liver cancer (hepatocellular carcinoma). Additionally, in 2013 sorafenib was approved to treat latestage (metastatic) differentiated thyroid cancer by the U.S. Food and Drug Administration (FDA) and The European Medicines Agency's Committee for Medicinal Products for Human Use (CHMP), (www. fda.gov/Drugs/ApprovedDrugs/ucm37654.htm) [2,3].

Multi Targeted kinase inhibitors such as: sorafenib, sunitinib, vandetanib, pazopanib, and axitinib are currently recommended in the Guidelines for Thyroid Carcinoma for patients with metastatic differentiated thyroid carcinoma (see NCCN.org). Between them, sorafenib constitutes the first line treatment option in advanced, radioiodine-refractory and metastatic epithelial thyroid tumors, because has a significant improves progression-free survival in these tumors. However, the clinical trials confirmed that sorafenib had serious adverse events like the development of a second primary cancer, difficult breathing, and pleural effusion [2-6]. Therefore, investment on new formulations designed to deliver sorafenib in a safe and targeted fashion merits special attention to the scientific community. Nanotechnology offers a promising and intriguing approach in the area of nanomedicine by delivering drugs in a targeted fashion to the malignant cells, and therefore, reducing the common side effects associated with anti-cancer drugs [7]. Thus, we have elaborated sorafenib loaded PLGA nanoparticles (Sor-NPs) covalently attached with cetuximab (Sor-NPs-Cetux) to deliver in a targeted fashion sorafenib into undifferentiated/anaplastic thyroid carcinoma

*Corresponding author: Jose Luis Pedraz, Ph.D. Laboratory of Pharmacy and Pharmaceutical Technology, Faculty of Pharmacy, University of the Basque Country, 01006, Vitoria-Gasteiz, Spain, Tel: 34-945013091; Fax: 34-945013040; E-mail: joseluis.pedraz@ehu.es

Alberto de Leiva Hidalgo, Ph.D. Grupo de Investigación Endocrinología y Diabetes del Hospital Sant-Pau -Universidad Autonoma de Barcelona, Spian, Tel: 34 935565660; E-mail: aleiva@santpau.es

Received February 16, 2015; Accepted March 16, 2015; Published March 28, 2015

Citation: Mato E, Puras G, Bell O, Agirre M, Hernández RM, et al. (2015) Selective Antitumoral Effect of Sorafenib Loaded PLGA Nanoparticles Conjugated with Cetuximab on Undifferentiated/Anaplastic Thyroid Carcinoma Cells. J Nanomed Nanotechnol 6: 281. doi:10.4172/2157-7439.1000281

Copyright: (C) 2015 Mato E, et al. This is an open-access article distributed unde the terms of the Creative Commons Attribution License, which permits unrestricted use, distribution, and reproduction in any medium, provided the original author and source are credited. 
Citation: Mato E, Puras G, Bell O, Agirre M, Hernández RM, et al. (2015) Selective Antitumoral Effect of Sorafenib Loaded PLGA Nanoparticles Conjugated with Cetuximab on Undifferentiated/Anaplastic Thyroid Carcinoma Cells. J Nanomed Nanotechnol 6: 281. doi:10.4172/21577439.1000281

cells that overexpress the epithelial growth factor receptor (EGFR). Monoclonal antibody cetuximab against EGFR, highly over expressed in undifferentiated/anaplastic thyroid carcinoma cells, was selected as a targeting agent to be covalently attached on the surface of the Sor-NPs due to its flattering properties for the treatment of many cancer types such as pancreatic cancer, non-small cell lung cancer or squamous cell carcinoma of the head and neck [8-10].

Moreover, cetuximab has been approved by the FDA for the treatment of patients affected by EGFR-positive colorectal cancer, underlying the relevance of this approach to other malignancies [11]. Sor-NPs were obtained by the single emulsion evaporation method and characterized in terms of size, charge, morphology, drug entrapment efficiency and in vitro drug release. Resulted nanoparticles were surface conjugated with monoclonal antibody cetuximab (Sor-NPs-Cetux) by EDC/Sulfo-NHS cross linking chemistry. Cellular uptake studies of fluorescent (6-coumarin) PLGA nanoparticles and cetuximab conjugated fluorescent PLGA nanoparticles were performed on both thyroid anaplastic (CAL-62) and normal thyroid cells (Nthy-ori 3-1). Finally, in vitro antiproliferation assays were performed to evaluate cytotoxicity of Sor-NPs and Sor-NPs-Cetux on both CAL-62 and Nthy-ori 3-1 cells.

\section{Materials and Methods}

\section{Materials}

Sorafenib tosylate was suppliued by Deltaclon (Madrid, Spain). Cetuximab (Erbitux ${ }^{\circledR} 5 \mathrm{mg} / \mathrm{ml}$ ) was obtained from Merck (Madrid, Spain). The polymer poly $\left({ }_{D, L}\right.$-lactide-co-glycolide) (PLGA, Resomer ${ }^{\mathbb{B}}$ RG 503, Mw 33,900) with a copolymer ratio of 50:50 (lactic/glycolic) and an intrinsic viscosity of $0.8 \mathrm{dl} / \mathrm{g}$ in $\mathrm{CHCl}_{3}$ was supplied by Boehringer Ingelheim K.G (Ingelheim, Germany). Polyvinyl alcohol (PVA, MW 30,000-70,000), dichloromethane, dimethyl sulfoxide, 1-ethyl-3-(3-dimethylaminopropyl)carbodiimide hydrochloride (EDC), N-hydroxysulfosuccinimide (Sulfo-NHS) and 6-coumarin were supplied by Sigma Chemical Co (St. Louis, MO, USA). The micro BCA assay kit was purchased from Pierce by Teknovas (Bilbao, Spain). All other chemical were analytical grade and were supplied by Panreac S.A (Barcelona, Spain).

\section{Preparation of sorafenib loaded PLGA nanoparticles}

Sor-NPs were prepared by a modification of the oil-in-water $(\mathrm{O} / \mathrm{W})$ single emulsion solvent evaporation method previously described [12]. Briefly, $20 \mathrm{mg}$ of Sorafenib were dissolved in $200 \mu \mathrm{l}$ of dimethyl sulfoxide and immediately sonicated for $15 \mathrm{~s}$ to ensure complete disolution. This solution was added to $3.800 \mu \mathrm{l}$ of dichloromethane containing $200 \mathrm{mg}$ of PLGA (5\% PLGA, w/v), which was then poured into 20 $\mathrm{ml}$ of a polyvinyl alcochol aqueous solution $(8 \%, \mathrm{w} / \mathrm{v})$ and sonicated for $60 \mathrm{~s}$ at $50 \mathrm{~W}$ (Branson Sonifier ${ }^{\circledR}$ ) over an ice bath. To favour the removal of the volatile organic solvents from the nanoparticles to the external phase, a $2 \%(\mathrm{w} / \mathrm{v})$ isopropanol solution was added and the system was stirred for $2 \mathrm{~h}$ on a magnetic stir plate at room temperature. The resulting nanoparticles were separated by ultra centrifugation at $30,000 \mathrm{rpm}, 4^{\circ} \mathrm{C}$ for $20 \mathrm{~min}$ (Sorvall Ultraspeed Centrifuge, Kendro, USA), followed by washing with double distilled water (the process was repeated three times). The recovered nanoparticulate suspension was freeze-dried (Lyo Beta, Telstar, Barcelona, Spain) with an aqueous solution of threalose $(5 \%, \mathrm{w} / \mathrm{v})$ for $24 \mathrm{~h}$.

\section{Characterization of sorafenib loaded PLGA nanoparticles}

Particle size, polydispersity index, and zeta potential measurements: Resulted Sor-NPs were characterized in terms of particle size, polydispersity index and zeta potential using a Malvern Zetasizer Nano ZS (Malvern Instrument, UK). Particle size was determined by dynamic light scattering based on backscatter detection optics at $173^{\circ}$. Briefly, $1 \mathrm{mg}$ of Sor-NPs was resuspended into $1 \mathrm{ml}$ of a $\mathrm{NaCl} 0.1 \mathrm{mM}$ aqueous solution. The refractive index (1.33) and the viscosity $(0.89)$ of ultrapure water at $25^{\circ} \mathrm{C}$ were used for data analysis performed in manual mode. The particle size reported as hydrodynamic diameter was obtained by cumulative analysis.

Zeta potential measurements were obtained by laser doppler velocimetry. Sor-NPs were resuspended as in size measurement experiments but employing disposable folded capillary cells for zeta analysis. Zeta potential measurements were also obtained in triplicate using the manual mode, with 20 measurements for each run. The Huckel approximation was used to support the calculation of the zeta potential. Only data that met the quality criteria according with the software programme (DTS 5.0, Zetasizer Nano system) were included in the study.

Transmission electron microscope (TEM) studies: Morphology of Sor-NPs was visualized using TEM analysis. Briefly, $5 \mu \mathrm{l}$ of the samples were adhered onto glow discharged carbon coated grids for 60 s. Remaining liquid was removed by blotting on paper filter and stained with $2 \%$ uranyl acetate for $60 \mathrm{~s}$ at $\mathrm{pH} 6.0$ to enhance the contrast. Samples were visualized under the microscope, TECNAI G2 20 TWIN (FEI, Eindhoven, The Netherlands), operating at an accelerating voltage of $200 \mathrm{KeV}$ in a bright-field image mode. Digital images were acquired with an Olympus SIS Morada digital camera.

Assessing the incorporation of sorafenib into the PLGA nanoparticles by HPLC-MS/MS: Sorafenib encapsulation efficiency into PLGA nanoparticles was estimated by an indirect method [13]. The free non-incorporated sorafenib in the supernatant after nanoparticles preparation was determined by HPLC with mass spectrometry detection. Erlotinib was used as internal standard (IS) in the HPLCMS/MS analysis.

The HPLC-MS/MS system consisted of the Waters Alliance 2795 HPLC system (Waters Corp., Milford, MA, USA) coupled with the Waters Quattro Premier mass spectrometer (Waters Corp., Milford, MA, USA).

Chromatographic separation was achieved at $30^{\circ} \mathrm{C}$ on a C18 column $\left(\mathrm{ACE}^{\circledR} \mathrm{C} 18,3 \mu \mathrm{m}, 30 \times 2.1 \mathrm{~mm}\right.$ ) using gradient elution with a mobile phase consisting of $0.1 \%$ formic acid (mobile phase A) and acetonitrile (mobile phase B). The flow rate was set at $0.8 \mathrm{ml} / \mathrm{min}$ and the total run time was $3.5 \mathrm{~min}$. The gradient elution started at $5 \% \mathrm{~B}$ for $0.2 \mathrm{~min}$, increased to $95 \%$ for $1 \mathrm{~min}$ and was held at the same percentage for 1 $\mathrm{min}$. Then, the system was equilibrated to initial conditions for $1.3 \mathrm{~min}$.

MS/MS detection was performed using electrospray ionization in positive mode (ESI+) and in multiple reaction monitoring (MRM) mode monitoring the ion transition from $\mathrm{m} / \mathrm{z} 465.3 \rightarrow 252.2$ for sorafenib and $\mathrm{m} / \mathrm{z} 394.3 \rightarrow 278.2$ for IS with dwell time of $200 \mathrm{~ms}$. The MS conditions were as follows: capillary voltage, $3.6 \mathrm{kV}$; cone voltage, $45.0 \mathrm{~V}$; source temperature, $100^{\circ} \mathrm{C}$; desolvation temperature, $400^{\circ} \mathrm{C}$; desolvation gas flow, $800 \mathrm{~L} / \mathrm{hr}$ and collision energy, $30 \mathrm{eV}$. Sorafenib quantification data were acquired and processed using MassLynx 4.0 software with QuanLynx v4.1 (Waters $\left.{ }^{\mathbb{R}}\right)$. Sorafenib determined by HPLC-MS/MS (free sorafenib) was subtracted from the total sorafenib added to prepare Sor-NPs (theoretical sorafenib). Therefore, the encapsulation efficiency was calculated using the following equation: 
Citation: Mato E, Puras G, Bell O, Agirre M, Hernández RM, et al. (2015) Selective Antitumoral Effect of Sorafenib Loaded PLGA Nanoparticles Conjugated with Cetuximab on Undifferentiated/Anaplastic Thyroid Carcinoma Cells. J Nanomed Nanotechnol 6: 281. doi:10.4172/21577439.1000281

$$
E E(\%)=\frac{\text { theoretical sorafenib }- \text { free sorafenib }}{\text { theoretical sorafenib }} \times 100
$$

Sorafenib content was expressed as the mass of incorporated sorafenib $(\mu \mathrm{g})$ per mg of lyophilized Sor-NPs.

\section{In vitro sorafenib release studies}

In order to carry out studies of sorafenib release from nanoparticles, $10 \mathrm{mg}$ of Sor-NPs were placed in test-tubes containing $1 \mathrm{ml}$ PBS $0.1 \mathrm{M}$, and tween $800.01 \%(\mathrm{w} / \mathrm{v}), \mathrm{pH}=7.4$. Nanoparticles suspensions were incubated at $37^{\circ} \mathrm{C}$ under continuous orbital rotation. At regular time intervals up to 40 days, the samples were spun at $30,000 \mathrm{rpm}, 4^{\circ} \mathrm{C}$ for 20 $\min$. The supernatants were withdrawn and the released sorafenib was determined by HPLC-MS/MS analysis as previously described (section 4.3.3). The same volume used for sorafenib determination was replaced with fresh buffer. The test was performed in three different batches.

\section{Preparation of immunonanoparticles (Sor-NPs-Cetux)}

To attach cetuximab monoclonal antibody to the Sor-NPs surface, EDC/Sulfo-NHS cross linking chemistry was employed [14]. Briefly, $40 \mathrm{mg}$ of Sor-NPs were resuspended in $4 \mathrm{mls}$ of MES buffer $(0.1 \mathrm{M}$, $0.5 \mathrm{M} \mathrm{NaCl}, \mathrm{pH}=5.5$ ). Then, $1.6 \mathrm{mg}$ of EDC (final concentration 2 $\mathrm{Mm}$ ) was directly added to the nanoparticles suspension, resulting in a 10 -fold molar excess of EDC to PLGA. Immediately, $4.4 \mathrm{mg}$ of Sulfo-NHS (final concentration $5 \mathrm{Mm}$ ) were added to the resulting SorNPs suspension, and the components were mixed under agitation on a magnetic plate for $30 \mathrm{~min}$ to allow the reaction. To inactivate EDC, $5 \mu \mathrm{l}$ of 2-mercaptoethanol (final concentration $20 \mathrm{Mm}$ ) were added. Then, the sample was ultracentrifuged at $30,000 \mathrm{rpm}, 4^{\circ} \mathrm{C}$ for $20 \mathrm{~min}$ to remove the unreacted EDC, Sulfo-NHS and 2-mercaptoethanol from the sediment. The process was repeated three times, and the sediment was washed each time with $1 \mathrm{ml}$ PBS $0.1 \mathrm{M}, 0.15 \mathrm{M} \mathrm{NaCl}$. Finally, to dissolve the pellet obtained after last centrifugation, $1 \mathrm{ml}$ of cetuximab solution $(1 \mathrm{mg} / \mathrm{ml}$, in PBS $0.1 \mathrm{M})$ was added and left under agitation for $2 \mathrm{~h}$ on a magnetic stir plate at room temperature, and then incubated overnight at $4^{\circ} \mathrm{C}$. Next day, to remove the unconjugated cetuximab, the suspension was ultracentrifuged at $30.000 \mathrm{rpm}, 4^{\circ} \mathrm{C}$ for $20 \mathrm{~min}$. The process was repeated three times, and the sediment was washed each time with $1 \mathrm{ml}$ PBS $0.1 \mathrm{M}, 0.15 \mathrm{M} \mathrm{NaCl}$. The supernatant was collected for the estimation of unconjugated cetuximab, and the resulted pellet was lyophilized with an aqueous solution of threalose (5\%,w/v) for $24 \mathrm{~h}$.

Characterization of Sor-NPs-Cetux immunonanoparticles: Resulted immunonanoparticles were characterized in terms of particle size, PDI and morphology as previously described (section 4.3.1 and 4.3.2).

Quantification of cetuximab conjugated on the surface of nanoparticles: The colorimetric microBCA protein assay kit was used to determine the amount of unbound cetuximab in the supernatant by spectrophotometry (Infinite M200 microplate reader, Tecan GENios, Switzerland). Free determined cetuximab was subtracted from the total amount of cetuximab added (theoretical cetuximab) to obtain Sor-NPs-Cetux immunonanoparticles. Therefore, cetuximab content was expressed as the mass of incorporated cetuximab $(\mu \mathrm{g})$ per mg of lyophilized nanoparticles. A sample collected from the supernatant of Sor-NPs without cetuximab was used as a control. The results were compared to a standard curve of cetuximab solution in the concentration range from $5 \mu \mathrm{g} / \mathrm{ml}$ to $100 \mu \mathrm{g} / \mathrm{ml}$.

\section{Preparation of 6-coumarin loaded nanoparticles and cetuximab conjugated 6-coumarin nanoparticles}

In order to determine the cellular uptake of nanoparticles, the fluorescent dye 6-coumarine was added to the DMSO solution $(0.05 \%$ $\mathrm{w} / \mathrm{v}$ ) instead of sorafenib, and the same procedure previously described (section 4.2) was followed to obtain fluorescent nanoparticles. Resulted fluorescent 6-coumarin loaded nanoparticles and cetuximab conjugated 6-coumarin nanoparticles were physicochemically characterized in terms of size, PDI and morphology (section 4.3.1 and 4.3.2).

\section{Cells cultures}

Cell Lines (CAL-62 and Nthy-ori 3-1): The human thyroid follicular epithelial cell line (Nthy-ori 3-1) was provided by Dr. Pilar Santisteban (CSIC, Madrid) and the human epithelial anaplastic thyroid cancer (CAL-62) cell line was provided by Leibniz- Institut DSMZ GmbH (ACC 448). The short tandem repeats (STRs) of Nthyori 3-1 cell line was analyzed following the manufacturer's instructions using the protocols for the GeneAmp ${ }^{\circledR}$ PCR System 2400 Thermal Cycler (Perkin Elmer/Applied Biosystems, Waltham, MA) and the ABI PRISM ${ }^{\circledR} 310$ Genetic Analyzer (Perkin Elmer/Applied Biosystems, Waltham, MA) and software package Genemapper 4.1 (Applied Biosystems, Carlsbad, CA, USA). The STR of Nthy-ori 3-1 cell line was matched with the results reported in previous studies [15].

Nthy-ori 3-1 cell line was cultured in RPMI 1640 (w L-glutamine), supplemented with $10 \%$ fetal bovine serum and $2 \%$ streptomycin/ penicillin. CAL-62 was cultured in Dulbecco's modified Eagle's medium (DMEM; Gibco, Invitrogen, Carlsbad, CA, USA) supplemented with $10 \%$ heat-inactivated fetal calf serum (FCS; Gibco), 20 mM L-GlutaMaxI (Gibco, Invitrogen Carlsbad, CA, USA), and 1\% penicillin-streptomycin (Gibco, Invitrogen Carlsbad, CA, USA).

\section{Immunocitochemistry}

Cellular suspensions of the Nthy-ori 3-1 and CAL-62 were centrifuged onto glass slides (cytospin) and fixed and rinsed with $4 \%$ paraformaldehyde and PBS solution, respectively. Afterwards, cells were blocked for $10 \mathrm{~min}$ at room temperature in a solution containing $1 \%$ BSA and $0.2 \%$ saponin. The EGFR primary monoclonal antibody (sc-120 Santa Cruz Biotechnology, Inc) was diluted with a blocking solution (s3022, DAKO, Denmark), and incubated overnight at $4^{\circ} \mathrm{C}$. Monoclonal Anti-Human IgG (Fc specific)-Biotin antibody (clone HP-6017, Sigma-aldrich) and peroxidase-conjugated streptavidin from the DAKO Universal LSAB kit (DAKO, Denmark) were added for 20 min each. Finally, sections were incubated in 3'3-diaminobenzidine (DAB) for $5 \mathrm{~min}$, followed by hematoxylin counterstaining and mounting. Negative controls were performed by replacing the primary antibody with non-immune serum. The results were visualized on a Zeiss microscope (Wetzlar, Germany) using AxioVision (Carl Zeiss Vision, Munich, Germany).

\section{In Vitro cellular uptake}

CAL-62 and Nthy-ori 3-1cells were cultured in 6-well cell confocal culture plates (627860 Greiner Bio-One) with DMEM containing $10 \%(\mathrm{v} / \mathrm{v}) \mathrm{FCS}, 1 \%$ antibiotics (penicillin) at $37^{\circ} \mathrm{C}$ in an atmosphere containing $5 \% \mathrm{CO}_{2}$. A predetermined amount of 6-coumarin labelled PLGA nanoparticles (0.5 mg NPs or NPs-Cetux) were added to the cultures and immediately the intracellular translocation of the nanoparticles was examined by confocal laser scanning microscopy (Leica DMI 6000 inverted microscope, Germany). The confocal microscopy images were acquired with a Leica objective HCX PL APO 
Citation: Mato E, Puras G, Bell O, Agirre M, Hernández RM, et al. (2015) Selective Antitumoral Effect of Sorafenib Loaded PLGA Nanoparticles Conjugated with Cetuximab on Undifferentiated/Anaplastic Thyroid Carcinoma Cells. J Nanomed Nanotechnol 6: 281. doi:10.4172/21577439.1000281

CS 40x/1.4-0.6 oil UV (No: 15506188) (Leica) and epifluoresce filters I3 (BP 450-490, LP 515) green.

For the video image, the microscope was equipped with a live-cell incubation chamber maintaining a humidified atmosphere of $5 \% \mathrm{CO}_{2}$ and $37^{\circ} \mathrm{C}$ (PeCon, Ulm, Germany). For all settings, we used AOBS, Acusto-Optical-Beam-Splitter and argon laser, blue, laser class IIIb, wavelength $458 \mathrm{~nm}, 476 \mathrm{~nm}, 488 \mathrm{~nm}, 496 \mathrm{~nm}, 514 \mathrm{~nm}$. 6-coumarine (3-(2'-benzothiazolyl)-7-diethylaminocoumarin- MW 350,4 Da) labelled nanoparticles were excited at $450 \mathrm{~nm}$ emission with a $505 \mathrm{~nm}$ band-pass filter. Phase contrast images were recorded with excitation at $488 \mathrm{~nm}$ and detection in the transmission channel. Laser power for observation was $1 \%$ at $488 \mathrm{~nm}, 25 \mathrm{~mW}$ and $50 \%$ at $543 \mathrm{~nm}, 1 \mathrm{~mW}$. Settings were adjusted in a way that image pixels were not over or underexposed with the range indicator function. The uptake movies were generated with in the Leica System Type TCS P5, program LASAF software (Supplementary Movies 1 and 2) z-volum $4.94 \mu \mathrm{m}$, travel range $9000 \mu \mathrm{m}$, interval time $60 \mathrm{~min}$. For the uptake analysis, all intracellular fluorescence was masked and the increase in fluorescence intensity was processed using Image J software [16]. The histograms taken from the intracellular fluorescence in the movies were compared between nanoparticles (Sor-NPs versus Sor-NPs-Cetux).

\section{In Vitro cytotoxicity studies of Sor-NPs and Sor-NPs-Cetux}

The in vitro cytotoxicity of Sor-NPs and Sor-NPs-Cetux formulations was assessed by 3-(4,5-dimethylthuazol-2-yl)-2,5diphenyltetrazolium bromide assay (MTT) (Sigma, M6494, MO, USA). The cell lines (Nthy-ori 3-1 and CAL-62) were placed in 96-well plates with $200 \mu \mathrm{l}$ of media at a density of 1,500 cells per well. After 24 $\mathrm{h}$ of culture, the media was removed and fresh media with different concentrations of free sorafenib $(2.5,5,10 \mathrm{mM})$ and the nanoparticles (Sor-NPs and Sor-NPs-Cetux) $(5,10$ and $20 \mu \mathrm{M})$ were added. At the end of incubation $(72 \mathrm{~h}), 10 \mu \mathrm{L}$ of MTT $(12 \mathrm{mM})$ was added and the cells were incubated for $4 \mathrm{~h}$ at $37^{\circ} \mathrm{C}$. Subsequently, the formed formazan crystals were dissolved by shaking with $50 \mu \mathrm{L}$ of DMSO (Sigma aldrich D8418) to each well and mix thoroughly with the pipette and incubate at $37^{\circ} \mathrm{C}$ for $10 \mathrm{~min}$. The absorbance of each well was measured at $540 \mathrm{~nm}$ in an ELISA microplate reader (BIORAD). The cytotoxicity rate was calculated as in percentage between absorbance cell treated/ absorbance untreated cells $\mathrm{x}$ 100. In each experiment, untreated cells were used as a control.

\section{Results and Discussion}

\section{Physicochemical characterization of Sor-NPs}

Traditionally, the synthesis of targeted nanoparticles requires the previous formulation of drug entrapped nanoparticles, followed by surface decoration with the selected targeting ligands. The final performance of drug delivery systems strongly depends on the physicochemical properties; therefore, resulted Sor-NPs were characterized in terms of size, PDI, zeta potential and morphology (Figure 1). The incorporation of sorafenib into PLGA nanoparticles increased the final particle size from $217.3 \pm 0.52 \mathrm{~nm}$ (blank PLGA nanoparticles, Figure S1A) to $252.0 \pm 0.92 \mathrm{~nm}$ (Figure 1A), which is in agreement with data reported by Kim et al., who found that particle size of dextran/poly(dl-lactide-coglicolide) copolymer increased according to the content of sorafenib loaded [17].

Regarding PDI, a slight increase from 0.07 to 0.1 was observed upon the addition of sorafenib. The determination of this parameter merits special attention, since along with particle size, the PDI influences directly on some important parameters such as physical stability, cellular uptake pathway, drug release and biodistribution of nanoparticles [18]. Different factors such as the nature of the polymer and the surfactant, the homogenization procedure, or the solvent viscosity command the final particle size and the PDI. Therefore, the flexibility of the system gives us the chance to control the final nanoparticles size and PDI, according to our needs.

The mean zeta potential of Sor-NPs $(-14.6 \pm 0.75 \mathrm{mV}$, Figure $1 B)$, did not differ significantly from that obtained in blank PLGA nanoparticles $(-14.04 \pm 0.72 \mathrm{mV}$, Figure S1B). These data indicate that negative free carboxylic end groups located on the surface of the nanoparticles were not affected by the incorporation of sorafenib into the nanoparticles. Zeta potential value conditionates, among other important parameters, the stability of the nanosuspension, since high zeta potential values (either positive or negative), typically more than $20 \mathrm{mV}$, prevent aggregation by electrostatic repulsions [19]. However, other results provide evidence that zeta potential values around $10 \mathrm{mV}$ can stabilize the suspensions [20]. In order to increase the circulation time of nanoparticles in blood stream, protein adsorption with serum components should be circumvented to avoid aggregations that may be quickly cleared by macrophages before the drug reaches the target cells [21]. In general, it is well accepted that negatively charged nanoparticles avoid interactions with blood proteins.

When observed under TEM, both Sor-NPs (Figure 1C) and blank PLGA nanoparticles (Figure S1C) showed spherical morphology, with smooth uniform surface which indicates that the addition of sorafenib, did not alter the morphology of the PLGA nanoparticles. Smooth surface morphology, without pores, influences the in vitro and in vivo performance of nanoparticles, and indicates successful solvent evaporation [22]. Encapsulation efficiency, $57.72 \pm 0.74 \%$, and drug content, $52.46 \pm 0.66 \mu \mathrm{g}$ of sorafenib per mg of Sor-NPs (Table S1), were determined by an indirect method, in the supernatant obtained during the preparation process, because in our experimental conditions, components obtained after dissolving the nanoparticles in organic solvents hampered the determination of sorafenib content by HPLC due to the presence of interfering peaks [13]. The sorafenib entrapped into the PLGA nanoparticles is attributed mainly to the partition coefficient, and hence, its retention in the organic phase as the microspheres solidify; however, it also depends on many other factors such as the particle size of the nanoparticles, the lipohilicity of the drug entrapped or the preparation method, to name a few [12,23]. Recently, Kim et al have reported values of sorafenib encapsulation efficiency into dextran/poly(dl-lactide-coplycolide) copolymer around $35 \%$ by the nanoprecipitation-dialysis method [17].

\section{In vitro release profile of Sor-NPs}

In vitro sorafenib release from the nanoparticles was studied by the incubation method (Figure 2). We observed an initial sorafenib release about $48 \%$ of total sorafenib incorporated into the NPs after $24 \mathrm{~h}$. This burst effect is classically attributed to diffusion of the drug adsorbed or weakly bound to the surface of the nanoparticles [24]. By contrast, the slow release rate observed for next 20 days depends on the amount of the drug incorporated inside the NPs. The poor solubility of sorafenib in the release medium could explain the slow release rate observed [12]. Interestingly, a clear increase in the release of sorafenib was observed in the next 5 days, probably due to the degradation of the PLGA matrix during the later phases. Therefore, the composition of the polymer matrix affects to the degradation rate, and consequently, to the release profile [25]. At the end of the study (45 days), approximately $75 \%$ of the loaded sorafenib was released from NPs. The incomplete release of sorafenib from NPs may be explained precisely, by the low solubility of 
Citation: Mato E, Puras G, Bell O, Agirre M, Hernández RM, et al. (2015) Selective Antitumoral Effect of Sorafenib Loaded PLGA Nanoparticles Conjugated with Cetuximab on Undifferentiated/Anaplastic Thyroid Carcinoma Cells. J Nanomed Nanotechnol 6: 281. doi:10.4172/21577439.1000281

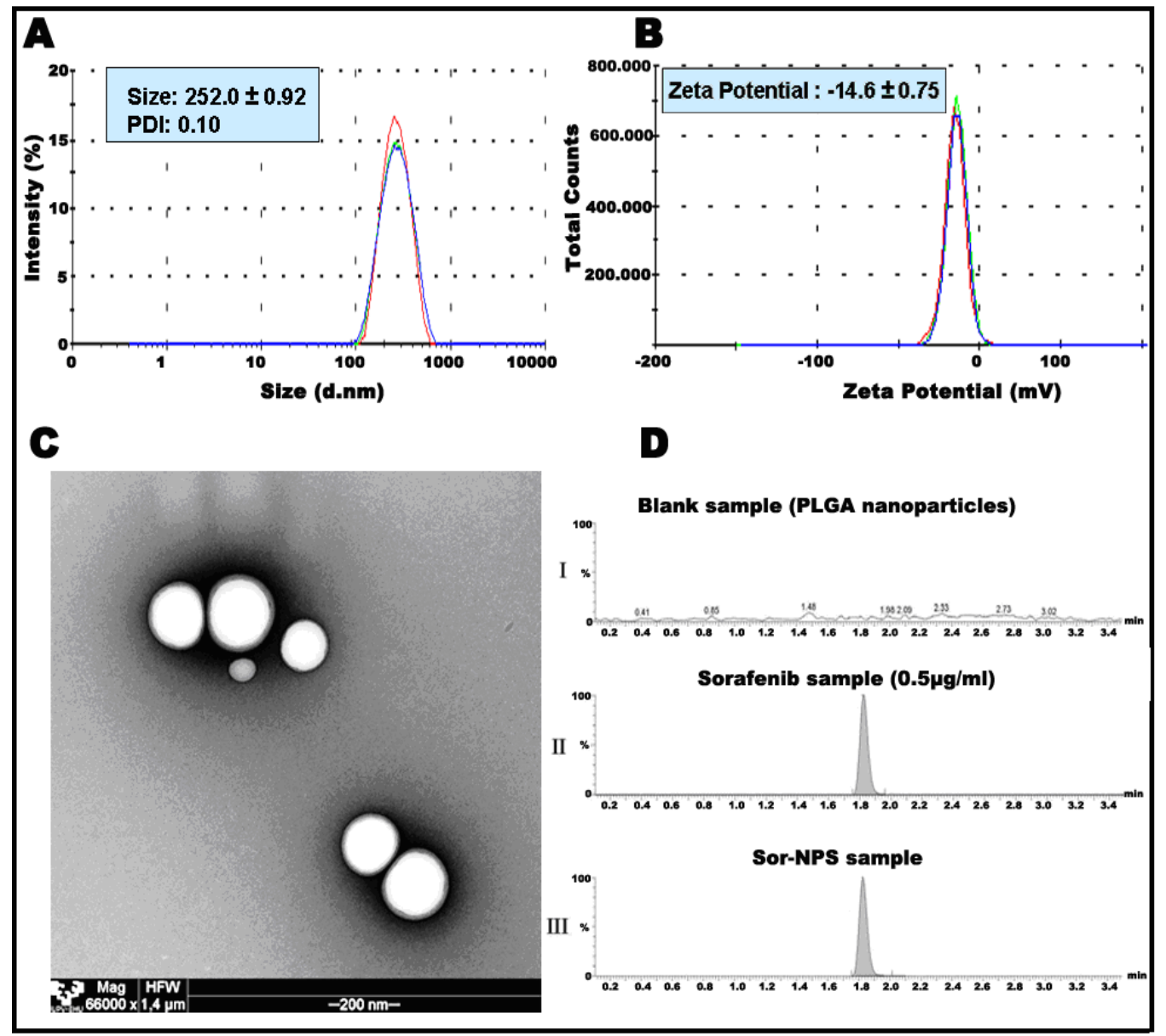

Figure 1: Physicochemical characterization of Sor-NPs in terms of A) sizedistribution, B) zeta potential, and C) morphology, (TEM, original magnification 66.000x). D) Representative HPLC-MS/MS chromatograms for sorafenib: (I) a blank sample (PLGA particle), (II) a calibrator sample spiked with $0.5 \mu \mathrm{g} / \mathrm{mL}$ sorafenib (III) a Sor-NPs sample 4 days after the start of the release study.

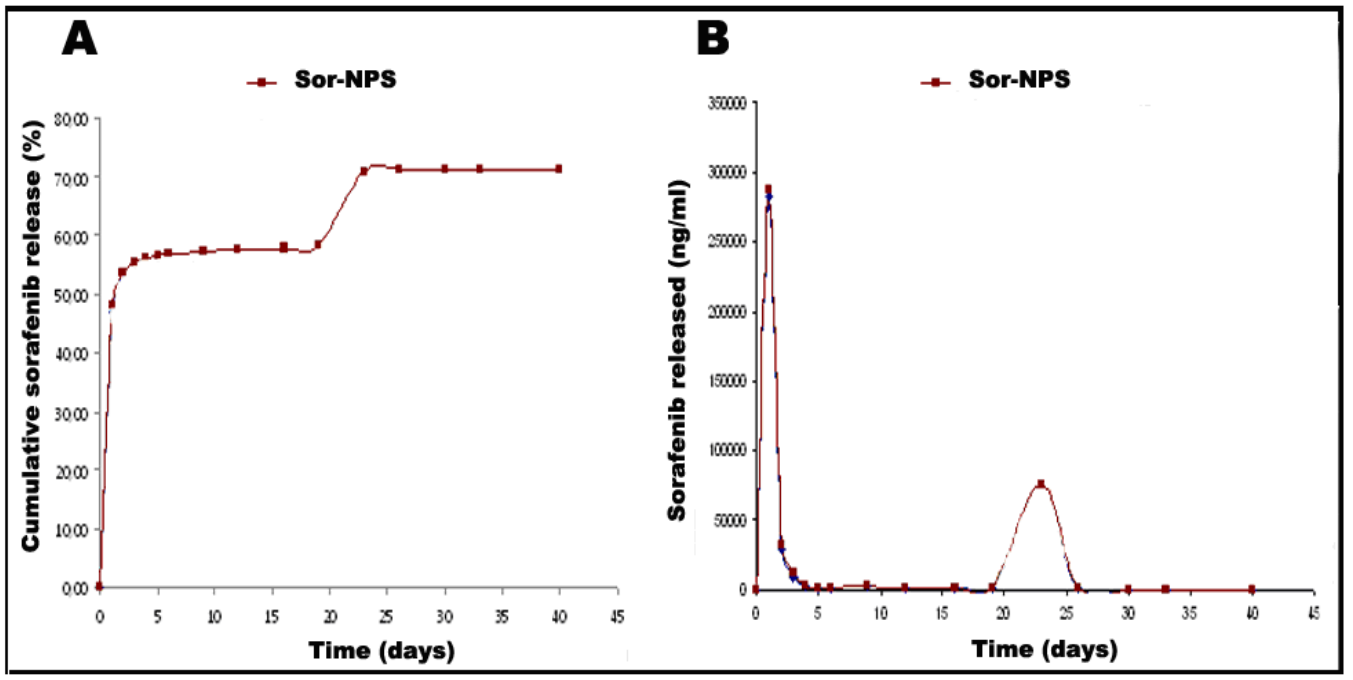

Figure 2: In vitro sorafenib release from Sor-NPs. A) Time course of thecumulative percentage of sorafenib released. B) Sorafenib released over the time. Values are represented as mean ( \pm standard deviation, SD) from three batches of each formulation. 
Citation: Mato E, Puras G, Bell O, Agirre M, Hernández RM, et al. (2015) Selective Antitumoral Effect of Sorafenib Loaded PLGA Nanoparticles Conjugated with Cetuximab on Undifferentiated/Anaplastic Thyroid Carcinoma Cells. J Nanomed Nanotechnol 6: 281. doi:10.4172/21577439.1000281

Page 6 of 10

sorafenib into the release medium.

\section{Physicochemical characterization of Sor-NPs-Cetux}

Since the preparation of Sor-NPs was successful in terms of particle size, PDI, zeta potential, morphology, entrapment efficiency and drug release, we decided to incorporate the monoclonal antibody cetuximab on the surface of the nanoparticles to target undifferentiated/anaplastic thyroid carcinoma cells that over express the EGFR, such as CAL-62 cells. A covalent binding approach based on the EDC/Sulfo-NHS cross linking chemistry was used to adsorb monoclonal antibody cetuximab on the surface of the Sor-NPs, in order to get Sor-NPs-Cetux. This chemical reaction is frequently used for coupling primary amino groups with carboxylates to obtain stable amide crosslinks [14]. We used a colorimetric microBCA protein assay kit to determine unbound cetuximab in the supernatant by spectrophotometry. Our data revealed that $51.11 \%$ of the cetuximab added was incorporated on the surface, which correspond to $17.03 \mu \mathrm{g}$ of cetuximab per mg of Sor-NPs (Figure 3 ). Our data are in agreement with those reported in the literature by other authors. Kocbeck et al., obtained $20 \mu \mathrm{g}$ of monoclonal antibody per mg of BSA loaded PLGA nanoparticles [14]. Interestingly, we observed a significant increase in the particle size from $252 \mathrm{~nm}$ (SorNPs, Figure 1A) to $277 \mathrm{~nm}$ (Sor-NPs-Cetux, Figure 3A) and in zeta potential from $-14.6 \mathrm{mV}$ (Sor-NPs, Figure 1B) to $-11.1 \mathrm{mV}$ (Sor-
NPs-Cetux, Figure 3B) when cetuximab was incorporated. The same tendency was reported by Acharya et al., when they incorporated a monoclonal antibody on the surface of PLGA nanoparticles loaded with rapamycin [26]. However, the changes observed by these authors in size (from $274 \mathrm{~nm}$ to $287 \mathrm{~nm}$ ) and in zeta potential (from $-13.8 \mathrm{mV}$ to $-12.2 \mathrm{mV}$ ) were less evident, probably due to the low antibody content (4.8 $\mu \mathrm{g}$ per mg of nanoparticles). We hypothesise that the increase in the particle size after cetuximab adsorption could be attributed by the greater space demanded by the antibody in the formulation, which in addition, neutralizes the carboxylic groups of the PLGA polymer, resulting in less negative systems.

\section{Characterization of 6-coumarin loaded PLGA nanoparticles and cetuximab conjugated 6-coumarin PLGA nanoparticles}

6-coumarin fluorescent dye has shown flattering properties for fluorescene/confocal microscope studies, due to its high fluorescent activity (low dye loading requirement) and to its low leak out from nanoparticles under in vitro conditions $[27,28]$. Therefore, we incorporated 6-coumarin fluorescent dye on the DMSO solution $(0.05 \%, w / v)$ instead of sorafenib to perform further cellular uptake studies. In order to assess if the incorporation of the 6-coumarin fluorescent dye could affect to important physicochemical parameter of the nanoparticles that command the cellular uptake, we determined

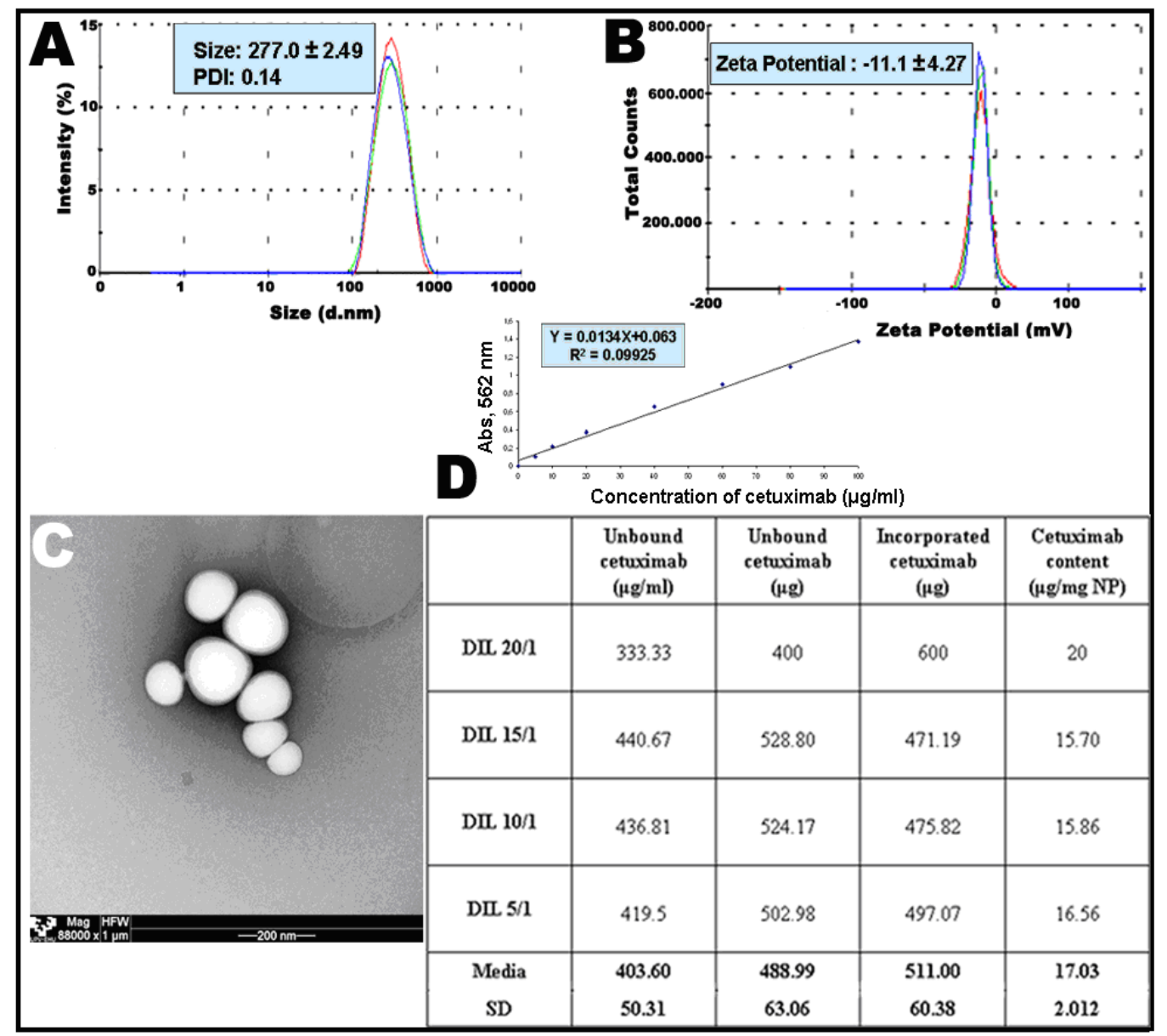

Figure 3: Physicochemical characterization of Sor-NPs-Cetux in terms of A)size distribution, B) zeta potential, and C) morphology (TEM, original magnification $88.000 \mathrm{x}$ ). D) Determination of cetuximab content by colorimetric micro BCA assay. 
Citation: Mato E, Puras G, Bell O, Agirre M, Hernández RM, et al. (2015) Selective Antitumoral Effect of Sorafenib Loaded PLGA Nanoparticles Conjugated with Cetuximab on Undifferentiated/Anaplastic Thyroid Carcinoma Cells. J Nanomed Nanotechnol 6: 281. doi:10.4172/21577439.1000281

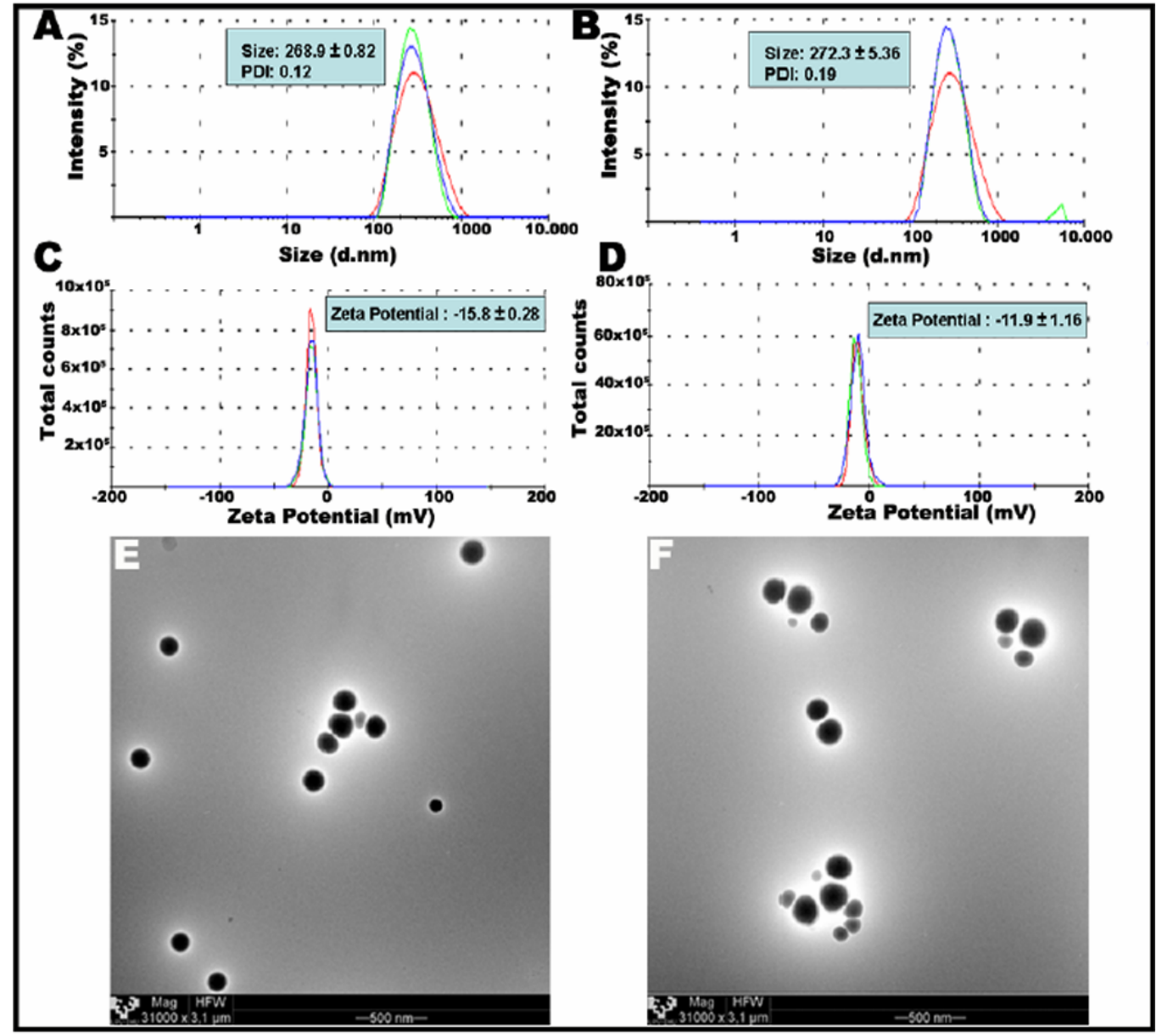

Figure 4: Physicochemical characterization of fluorescent PLGA NPs. (A, C, E)size distribution, zeta potential, and morphology (TEM, original magnification $31.000 x$ ) of 6-coumarin loaded PLGA nanoparticles. B, D, F) size distribution, zeta potential, and TEM (original magnification 31.000x) of cetuximab conjugated 6-coumarin loaded PLGA nanoparticles.

particle size, zeta potential and morphology of 6-coumarin loaded PLGA nanoparticles and cetuximab conjugated 6-coumarin PLGA nanoparticles (Figure 4). When compared with Sor-NPs, a negligent increase in both particle size from $252 \mathrm{~nm}$ (Figure 1A, Sor-NPs) to 268.9 (Figure 4A, 6-coumarine NPs) and in zeta potential from -14.6 $\mathrm{mV}$ (Figure 1B, Sor-NPs) to $-15.8 \mathrm{mV}$ (Figure 4C, 6-coumarine NPs) was observed. Regarding particles with cetuximab adsorbed on the surface, size (277 nm, Figure $3 \mathrm{~A})$ and zeta potential (-11.1 mV, Figure 3B) did not significantly change after replacing sorafenib by 6 -coumarin (size $272 \mathrm{~nm}$, Figure 4B and zeta $-11.9 \mathrm{mV}$ Figure 4D). All particles conserved the spherical and smooth morphology. Based on these data, we conclude that important physicochemical parameters that can affect to the final performance of the nanoparticles such as size, charge and morphology did not significantly vary upon the replacement of sorafenib by 6-coumarin dye; therefore, our fluorescent nanoparticles based on 6-coumarin represent an interesting approach to perform cellular uptake studies. Interestingly, we observed the same tendency described before (section 3.3), since the adsorption of cetuximab on the surface of the nanoparticles slightly increased the size and the zeta potential values.

\section{Expression levels of EGFR in CAL-62 and Nthy-ori 3-1 cell lines}

It is known that the EGFR is highly expressed in a variety of solid human tumours of epithelial origin and it is also correlated with the poor prognosis of the patients [29]. Despite that some studies about the expression levels of EGFR in epithelial thyroid cancer are controversial; most of them describe that their expression is higher than in normal thyroid tissue [30,31]. This finding has been supported by tissue arrays analysis, which confirms the overexpression of this receptor in anaplastic thyroid carcinoma [32]. This EGFR receptor is considered an attractive target for molecular therapy against tumoural cells [33].

The expression of EGFR in CAL-62 and Nthy-ori 3-1 cellular lines was analyzed by immunostained technique (Figure 5). As expected, the number and the signal of the EGFR positive cells were higher on thyroid anaplastic cells CAL-62 (Figures 5A and 5B) than on the Nthy-ori 3-1 cells (Figure 5C), this last cell line considered as a normal follicular thyroid cell.

\section{In vitro cellular uptake studies}

The cellular uptake of PLGA NPs and cetuximab conjugated PLGA 
Citation: Mato E, Puras G, Bell O, Agirre M, Hernández RM, et al. (2015) Selective Antitumoral Effect of Sorafenib Loaded PLGA Nanoparticles Conjugated with Cetuximab on Undifferentiated/Anaplastic Thyroid Carcinoma Cells. J Nanomed Nanotechnol 6: 281. doi:10.4172/21577439.1000281

Page 8 of 10

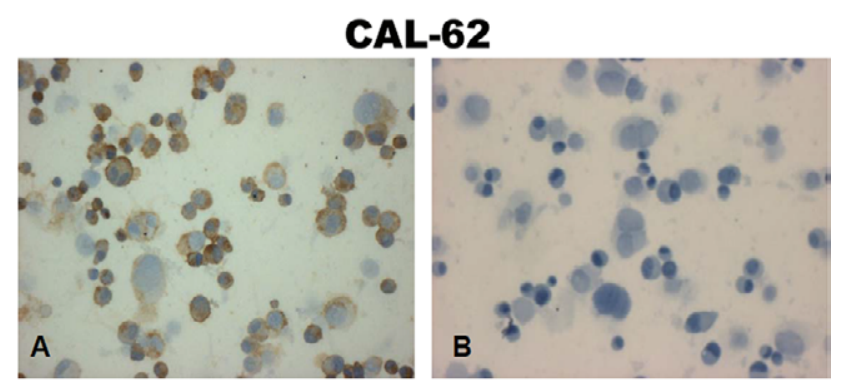

Nthy-ori 3-1

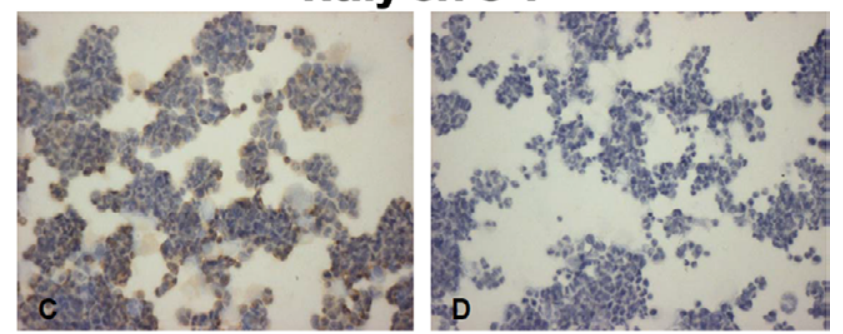

Figure 5: Image analysis of CAL-62 and Nthy-ori 3-1 cell lines immunostained with anti-human EGFR monoclonal antibody that recognizes a cell surface epitope of human receptor. (A-C) positive cells (B-D) Negative control. (Original magnification $\times 200$ ).

NPs into CAL-62 and Nthy-ori 3-1 cells were visualized by confocal laser scanning microscopy using 6-coumarin as a fluorescent marker over different time intervals. The images obtained by confocal laser scanning microscopy were analyzed by image J software and presented as histograms of mean fluorescence intensity [34] over the time (Figure 6) and confocal microscopy images (Figure 7). Additionally, video samples are included as supplementary data to show uptake studies (sample movies 1-2). The results in CAL-62 and Nthy-ori 3-1 cell lines treated with the nanoparticles showed that in both formulations (6-cumarin PLGA NPs and 6-cumarin PLGA-cetuximab NPs), the nanoparticles were quickly internalized and distributed into the cytoplasm after $15 \mathrm{~min}$ of the administration, without fluorescence signal in the nuclei of cells (data not shown). The kinetic study of the nanoparticles internalization in CAL-62 cells showed a fast uptake with a saturation plateau beginning at 16 minutes to 43 minutes of video capture when the cells were incubated with the 6-cumarin PLGA NPs (Figure 6A). This plateau observation suggestes that the cellular uptake of non-modified PLGA NPs is saturable. Moreover, this 6-coumarin PGLA NPs were visualized at $48 \mathrm{~h}$ into the cytoplasm of the cells (Figure $7 \mathrm{~A}_{1}$ ) but a faster decreased in the fluoresce intensity after 7 days of exposition was detected (Figure $7 \mathrm{~A}_{2}$ ). In contrast, the uptake of cetuximab modified PLGA NPs was slower but in constant progression. No plateau effect was detected between 1 to 181 minutes of the video capture (Figure 6B). The intracellular fluorescence was observed at $48 \mathrm{~h}$ of exposition in the cytoplasm of the cells (Figure $7 \mathrm{~B}_{1}$ ), and the signal was maintained at 7 days of uptake (Figure $7 \mathrm{~B}_{2}$ ). Therefore, our results show that the incorporation of cetuximab monoclonal antibody on the surface of the PLGA NPs clearly modify the enter uptake pathway on CAL-62 cells, probably due to specific interactions with EGFR over expressed in this cell line. However, further co-culture assays will be necessaries to validate or not this hypothesis.

Regarding Nthy-ori 3-1 cells, we observed a similar capture pattern of both nanoparticles (6-cumarin-labelled PLGA and 6-cumarin- labelled PLGA-cetuximab NPs), with a gradual increase of the fluorescence intensity in the cytoplasm of the cells (Figure 6A and $6 \mathrm{~B})$. Our data also showed a lost of the intensity fluorescence in the cytoplasm of the cells after 7 days of exposition (data not shown).

When comparing the uptake pattern between the two cell lines, we observed clear differences, since the mean fluorescence intensity in Nthy-ori 3-1 cells was clearly inferior than in CAL-62 cells (Figure 6) regardless the incorporation or not of cetuximab into the surface of the PLGA NPs. Several pathways in the internalization mechanisms and also in the intracellular trafficking between both cell lines could explain the differences observed.

\section{In Vitro cytotoxicity studies of Sor-NPs and Sor-NPs-Cetux}

To investigate the therapeutic potency of our sorafenib formulations, CAL-62 and Nthy-ori 3-1 cell lines were treated with free sorafenib, Sor-NPs and Sor-NPs-Cetux (Figure 8). The results of the toxic effect after 24 hours of incubation at 5, 10 and $20 \mu \mathrm{M}$ doses with the free drug produced a markedly decrease in the cellular viability from $89.2 \%$ to $21.81 \%$ and from $89.3 \%$ to $16.5 \%$ in both CAL- 62 and Nthy-ori 3-1 cells, respectively (Figure $8 \mathrm{~A}$ and $8 \mathrm{~B}$, triangles). However, when the cells were treated with Sor-NPs, we clearly observed a higher cytotoxic effect on Nthy-ori 3-1 cells (Figure 8B rhombus, 45\%, 30.0\% and $22 \%$ of cell viability at 5,10 and $20 \mu \mathrm{M}$ concentration) than in CAL-62 cells (Figure $8 \mathrm{~A}$ rhombus, $56 \%, 47 \%$ and $47 \%$ of cell viability at 5,10 and $20 \mu \mathrm{M}$ concentrations). Regarding the toxicity effect of Sor-NPs-Cetux, we observed a similar toxicity than the formulation without cetuximab on CAL-62 cells (Figure 8A squares, 56\%, $47 \%$ and $47 \%$ of cell viability at 5,10 and $20 \mu \mathrm{M}$ concentration), exhibiting the IC50 at arround $10 \mu \mathrm{M}$. However and interestingly, on Nthy-

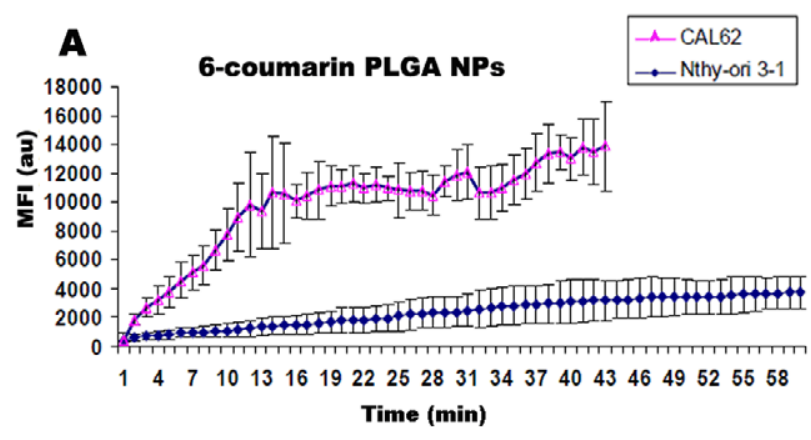

B Cetuximab 6-coumarin PLGA NPs

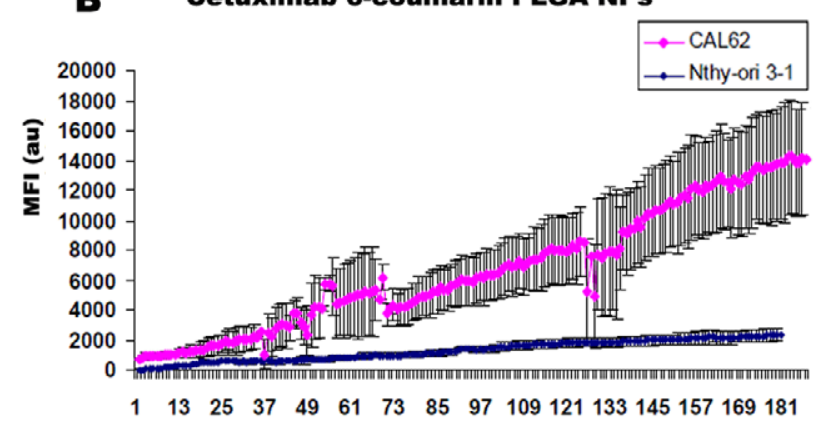

Figure 6: Time course of uptake of fluorescent PLGANPs in CAL-62 and Nthyori 3-1 cell lines. A) 6-coumarin loaded PLGA nanoparticles, (supplementary movie 1 in CAL-62 cells). B) cetuximab conjugated 6-coumarin loaded PLGA nanoparticles. (Supplementary movie 2 in CAL-62 cells). Data given as means \pm SE for 10 to 20 measurements of fluorescence intensity (au) in cellular spaces. Each point represents the mean \pm s.d. monitored over the time at a frame rate of one image every $20 \mathrm{~s}$. 
Citation: Mato E, Puras G, Bell O, Agirre M, Hernández RM, et al. (2015) Selective Antitumoral Effect of Sorafenib Loaded PLGA Nanoparticles Conjugated with Cetuximab on Undifferentiated/Anaplastic Thyroid Carcinoma Cells. J Nanomed Nanotechnol 6: 281. doi:10.4172/21577439.1000281

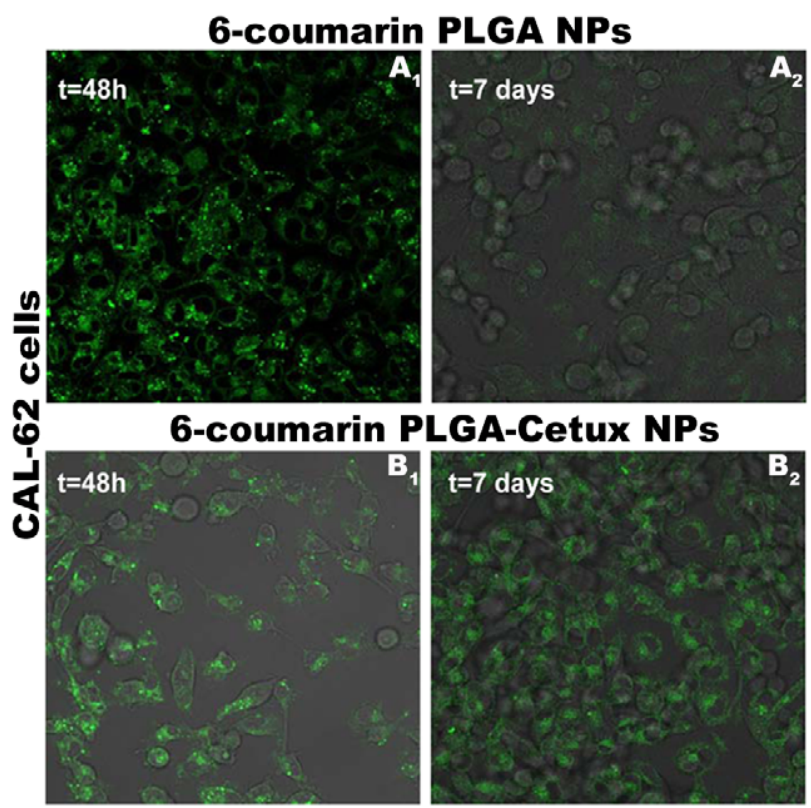

Figure 7: Confocal optical sections of timelapse movies after administration offluorescence labelled nanoparticles (6-coumarin PLGA NPs and 6-coumarin PLGA-Cetux NPs) at $\mathrm{t}=48$ hours and 7 days on CAL-62 and Nthy-ori 3-1 cell lines. (Original magnification $\mathrm{x} 200$ ).
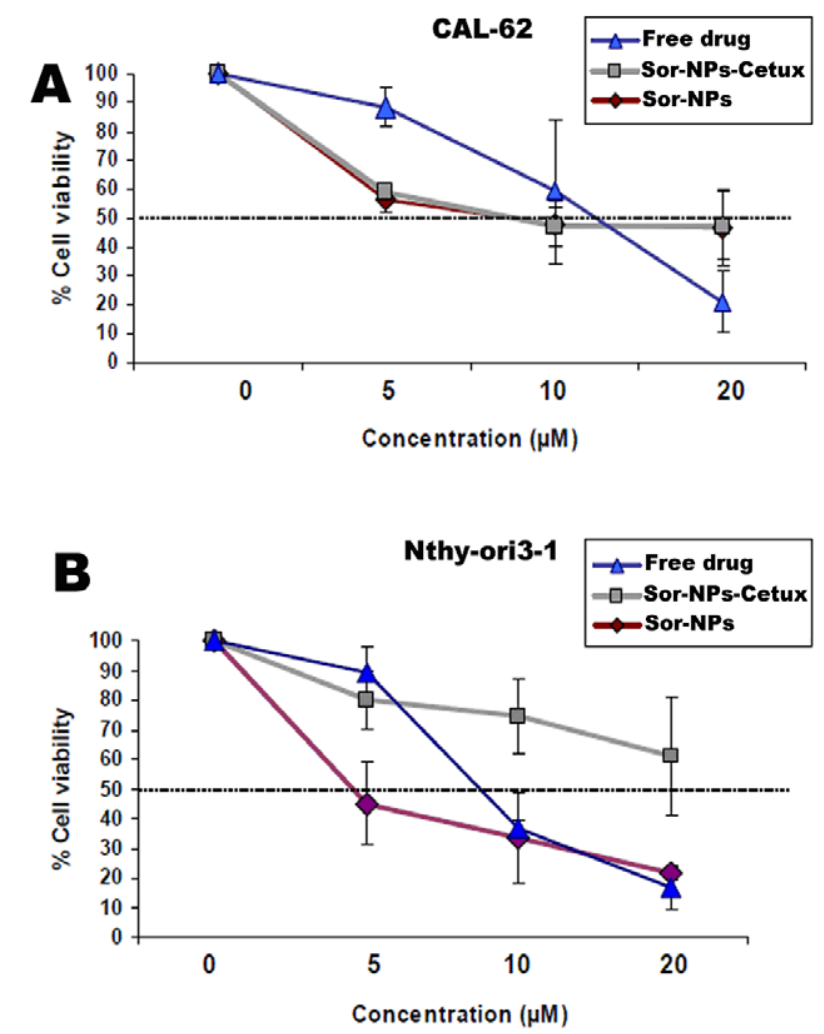

Figure 8: Cytotoxicity assay of the free sorafenib (triangles), Sor-NPsCetux(squares) Sor-NPs (rhombus) and after 24 hours of incubation at $5 \mu \mathrm{M}$, $10 \mu \mathrm{M}$ and $20 \mu \mathrm{M}$ in CAL-62 and Nthy-ori 3-1 cell lines. ori 3-1 cells, Sor-NPs-Cetux were clearly less toxic (Figure 8B squares, $80 \%, 78 \%$ and $65 \%$ of cell viability, without induction of IC50 at 5,10 and $20 \mu \mathrm{M}$ concentrations) than the formulation without cetuximab (Figure $8 \mathrm{~B}$ rhombus, $45 \%, 30.0 \%$ and $22 \%$ of cell viability at 5,10 and $20 \mu \mathrm{M}$ concentration). To summarize, our in vitro cytotoxicity study shows that free sorafenib formulation decreases viability of CAL62 thyroid anaplastic cells, and therefore, could be used for the treatment of undifferentiated/anaplastic thyroid carcinomas; However, the unselective cytotoxicity observed could hampers the clinical application of sorafenib for this purpose, since normal thyroid Nthy-ori 3-1 cells were equally affected by the administration of free sorafenib. The encapsulation of sorafenib into PLGA nanoparticles showed even a more toxic effect in normal thyroid Nthy-ori 3-1 cells than in CAL62 thyroid anaplastic cells. Therefore, a selective delivery of sorafenib to CAL62 thyroid anaplastic cells is required in order to avoid the common side effects of sorafenib [1,7]. Our Sor-NPs surface modified with monoclonal antibody cetuximab maintained the same toxicity levels of Sor-NPs in CAL62 thyroid anaplastic cells, but interestingly, were better tolerated than Sor-NPs in normal thyroid Nthy-ori 3-1 cells, which highlight the potential use of this novel system for the possible treatment of undifferentiated/ anaplastic thyroid carcinomas minimizing the side effects.

\section{Conclusion}

Drug targeting represent a challenging approach with promising potential to circumvent some problems associated with many side effects of antineoplastics drugs. In this study, we have elaborated and deeply characterized in different physicochemical and biological terms PLGA nanoparticles surface modified with monoclonal antibody cetuximab to deliver in a targeted fashion sorafenib into undifferentiated/anaplastic thyroid carcinoma cells. Our results showed a higher specificity of the nanoparticles decorated with cetuximab in the anaplastic cells line (CAL-62) that overexpress EGFR than in the normal thyroid cell line (Nthy-ori 3-1 cells), which have the level of expression low or practically null. This different action suggests the use of this receptor as a model for drug delivery systems with targeting ability in the thyroid anaplastic cells described previously.

\section{Acknowledgements and Disclosures}

This project was partially supported by the University of the Basque Country UPVIEHU (UFI 11/32), and the Spanish FIS Grant from the Ministry of Health and Consumer Affairs FIS09/02286, Agència de Gestió d'Ajuts Universitaris i de Recerca (AGAUR) 20092014 SGR 569, Fundación ECO and CIBER-BBN (ISCIII). The technical and human support provided by SGlker (UPV/EHU) and is gratefully acknowledged. Authors also wish to thank the intellectual and technical assistance from the Platform for Drug Formulation (NANBIOSIS) CIBER-BBN and confocal platform from IB-Sant Pau (Barcelona).

\section{References}

1. Brenner $\mathrm{H}$ (2002) Long-term survival rates of cancer patients achieved by the end of the 20th century: a period analysis. Lancet 360: 1131-1135.

2. Brose MS, Nutting CM, Jarzab B, Elisei R, Siena S, et al. (2014) Sorafenib in radioactive iodine-refractory, locally advanced or metastatic differentiated thyroid cancer: a randomised, double-blind, phase 3 trial. Lancet 384: 319-328.

3. Thomas L, Lai SY, Dong W, Feng L, Dadu R, et al. (2014) Sorafenib in metastatic thyroid cancer: a systematic review. Oncologist 19: 251-258.

4. Li Y, Gao ZH, Qu XJ (2015) The adverse effects of sorafenib in patients with advanced cancers. Clin Pharmacol Toxicol 116: 216-221.

5. Tuttle RM, Haddad RI, Ball DW, Byrd D, Dickson P, et al. (2014) Thyroid carcinoma, version 2.2014. J Natl Compr Canc Netw 12: 1671-1680.

6. Lee HJ, Ryu H, Choi YS, Song IC, Yun HJ, et al. (2015) Sorafenib for patients with differentiated thyroid cancer. Lancet 385: 228. 
Citation: Mato E, Puras G, Bell O, Agirre M, Hernández RM, et al. (2015) Selective Antitumoral Effect of Sorafenib Loaded PLGA Nanoparticles Conjugated with Cetuximab on Undifferentiated/Anaplastic Thyroid Carcinoma Cells. J Nanomed Nanotechnol 6: 281. doi:10.4172/21577439.1000281

Page 10 of 10

7. Cegnar M, Kristl J, Kos J (2005) Nanoscale polymer carriers to deliver chemotherapeutic agents to tumours. Expert Opin Biol Ther 5: 1557-1569.

8. Patra CR, Bhattacharya R, Wang E, Katarya A, Lau JS, et al. (2008) Targeted delivery of gemcitabine to pancreatic adenocarcinoma using cetuximab as a targeting agent. Cancer Res 68: 1970-1978.

9. Kim ES, Lu C, Khuri FR, Tonda M, Glisson BS, et al. (2001) A phase II study of STEALTH cisplatin (SPI-77) in patients with advanced non-small cell lung cancer. Lung Cancer 34: 427-432.

10. Herbst RS, Kim ES, Harari PM (2001) IMC-C225, an anti-epidermal growth factor receptor monoclonal antibody, for treatment of head and neck cancer. Expert Opin Biol Ther 1: 719-732.

11. Rocha-Lima CM, Soares HP, Raez LE, Singal R (2007) EGFR targeting of solid tumors. Cancer Control 14: 295-304.

12. Hombreiro-Pérez M, Siepmann J, Zinutti C, Lamprecht A, Ubrich N, et al. (2003) Non-degradable microparticles containing a hydrophilic and/or a lipophilic drug: preparation, characterization and drug release modeling. J Control Release 88: 413-428.

13. Mainardes RM, Evangelista RC (2005) PLGA nanoparticles containing praziquantel: effect of formulation variables on size distribution. Int $\mathrm{J}$ Pharm 290: 137-144.

14. Kocbek P, Obermajer N, Cegnar M, Kos J, Kristl J (2007) Targeting cancer cells using PLGA nanoparticles surface modified with monoclonal antibody. J Control Release 120: 18-26.

15. Meireles AM, Preto A, Rocha AS, Rebocho AP, Máximo V, et al. (2007) Molecular and genotypic characterization of human thyroid follicular cel carcinoma-derived cell lines. Thyroid 17: 707-715.

16. Collins TJ (2007) ImageJ for microscopy. Biotechniques 43: 25-30.

17. Kim do H, Kim MD, Choi CW, Chung CW, Ha SH, et al. (2012) Antitumor activity of sorafenib-incorporated nanoparticles of dextran/poly(dl-lactide-co-glycolide) block copolymer. Nanoscale Res Lett 7: 91.

18. Feng SS1 (2004) Nanoparticles of biodegradable polymers for new-concept chemotherapy. Expert Rev Med Devices 1: 115-125.

19. Patil S, Sandberg A, Heckert E, Self W, Seal S (2007) Protein adsorption and cellular uptake of cerium oxide nanoparticles as a function of zeta potential. Biomaterials 28: 4600-4607.

20. Quaglia F, Ostacolo L, Mazzaglia A, Villari V, Zaccaria D, et al. (2009) The intracellular effects of non-ionic amphiphilic cyclodextrin nanoparticles in the delivery of anticancer drugs. Biomaterials 30: 374-382.

21. Lee AL, Wang Y, Cheng HY, Pervaiz S, Yang YY (2009) The co-delivery of paclitaxel and Herceptin using cationic micellar nanoparticles. Biomaterials 30 : 919-927.

22. Huo D, Deng S, Li L, Ji J (2005) Studies on the poly(lactic-co-glycolic) acid microspheres of cisplatin for lung-targeting. Int J Pharm 289: 63-67.

23. Liggins RT, D'Amours S, Demetrick JS, Machan LS, Burt HM (2000) Paclitaxel loaded poly(L-lactic acid) microspheres for the prevention of intraperitoneal carcinomatosis after a surgical repair and tumor cell spill. Biomaterials 21 1959-1969.

24. Parveen S, Sahoo SK (2008) Polymeric nanoparticles for cancer therapy. J Drug Target 16: 108-123.

25. Igartua M, Hernández RM, Esquisabel A, Gascon AR, Calvo MB, et al. (1997) Influence of formulation variables on the in-vitro release of albumin from biodegradable microparticulate systems. J Microencapsul 14: 349-356.

26. Acharya S, Dilnawaz F, Sahoo SK (2009) Targeted epidermal growth factor receptor nanoparticle bioconjugates for breast cancer therapy. Biomaterials 30 5737-5750.

27. Davda J, Labhasetwar V (2002) Characterization of nanoparticle uptake by endothelial cells. Int J Pharm 233: 51-59.

28. Desai MP, Labhasetwar V, Walter E, Levy RJ, Amidon GL (1997) The mechanism of uptake of biodegradable microparticles in Caco-2 cells is size dependent. Pharm Res 14: 1568-1573.

29. Normanno N, Campiglio M, Maiello MR, De Luca A, Mancino M, et al. (2008) Breast cancer cells with acquired resistance to the EGFR tyrosine kinase inhibitor gefitinib show persistent activation of MAPK signaling. Breast Cancer Res Treat 112: 25-33.

30. Aasland R, Akslen LA, Varhaug JE, Lillehaug JR (1990) Co-expression of the genes encoding transforming growth factor-alpha and its receptor in papillary carcinomas of the thyroid. Int J Cancer 46: 382-387.

31. Gorgoulis V, Aninos D, Priftis C, Evagelopoulou C, Karameris A, et al. (1992) Expression of epidermal growth factor, transforming growth factor-alpha and epidermal growth factor receptor in thyroid tumors. In Vivo 6: 291-296.

32. Schiff BA, McMurphy AB, Jasser SA, Younes MN, Doan D, et al. (2004) Epidermal growth factor receptor (EGFR) is overexpressed in anaplastic thyroid cancer, and the EGFR inhibitor gefitinib inhibits the growth of anaplastic thyroid cancer. Clin Cancer Res 10: 8594-8602.

33. Woodburn JR (1999) The epidermal growth factor receptor and its inhibition in cancer therapy. Pharmacol Ther 82: 241-250.

34. Schneider CA, Rasband WS, Eliceiri KW (2012) NIH Image to ImageJ: 25 years of image analysis. Nat Methods 9: 671-675. 